\title{
O jovem e a universidade em Angola: a trajetória dos jovens angolanos do interior do país no curso de Psicologia da Universidade Agostinho Neto
}

The young and the university in Angola: the trajectory of the youth from Angola inner provinces in Psychology Studies at Agostinho Neto University

Los jóvenes y la universidad en Angola: la trayectoria de los jóvenes angoleños de las pequeñas ciudades del país en el curso de Psicología de la Universidad Agostinho Neto

\author{
Pedro Félix Chioia ${ }^{*}$ \\ Maria Ignez Costa Moreira ${ }^{* *}$
}

\begin{abstract}
Resumo
Neste texto, são discutidos os impactos vividos pelos jovens das províncias angolanas que migraram para Luanda, a fim de estudar Psicologia na Universidade Agostinho Neto. Buscou-se compreender as suas trajetórias e expectativas em relação à universidade e ao exercício profissional. Os sujeitos pesquisados são, em sua maioria, a primeira geração de suas famílias a entrar na universidade, o que representa uma realização pessoal e coletiva. As estratégias metodológicas da pesquisa compreenderam o uso de questionários, entrevistas individuais e coletivas, além de pesquisa bibliográfica e documental. Os universitários revelaram suas expectativas de desenvolvimento pessoal, de inclusão no mercado de trabalho e de acesso à pós-graduação. Os estudantes acreditam que os psicólogos são importantes para a sociedade angolana, marcada pela longa guerra civil, pois poderão contribuir para a superação do sofrimento emocional e para a organização social em tempos de paz.
\end{abstract}

Palavras-chave: Juventude. Universitários angolanos. Trajetória. Curso de Psicologia.

\begin{abstract}
In this text, we discuss the impacts experienced by young people of provinces from Angola who migrated to Luanda, in order to study Psychology at Agostinho Neto University. We tried to understand their trajectories and expectations regarding the University and the professional practice of these
\end{abstract}

\footnotetext{
Texto recebido em março 2013 e aprovado para publicação em setembro de 2014.

Mestre em Psicologia pela PUC Minas, Brasil; professor e chefe do Departamento de Ensino e Investigação Científica na Graduação e Pós-graduação, na Escola Superior Politécnica de Malanje, Angola. Endereço: Universidade Lueji A’Ankonde ULAN. Escola Superior Politécnica de Malanje, Malanje, Angola. E-mail: pedroirmao@hotmail.com.br.

* Doutora em Psicologia Social pela PUC São Paulo, professora do Programa de Pós-graduação em Psicologia da PUC Minas. Endereço: Avenida Itaú, 525 - Prédio Redentoristas - 1o subsolo - Bairro Dom Bosco, Belo Horizonte-MG, Brasil. CEP: 30730-280. E-mail: maigcomo@uol.com.br.
} 
young people. The subjects of the research are mostly the first generation of their families to enter university, which is a personal and collective achievement. Methodological strategies used in the research included the use of questionnaires, individual and group interviews, as well as bibliographic and documentary research. The students revealed their expectations for personal development, inclusion in the labor market and access to graduate studies. Students believe that psychologists are important for Angola and its people, shaken by the long civil war, because they will be able to contribute to overcome emotional distress and contribute to social organization in times of peace.

Keywords: Youth. University students in Angola. Trajectory. Psychology studies.

\section{Resumen}

En este texto se discuten los impactos que experimentan los jóvenes de las provincias angoleñas que emigraron a Luanda, con el fin de estudiar Psicología en la Universidad Agostinho Neto. Tratamos de comprender sus trayectorias y expectativas con respecto a la Universidad y a la práctica profesional. Los sujetos de estudio son, en su mayoría, la primera generación de sus familias que acceden a la universidad, lo cual es un logro personal y colectivo. Las estrategias metodológicas de la investigación comprendieron el uso de cuestionarios, de entrevistas individuales y de grupo, así como la investigación bibliográfica y documental. Los universitarios revelaron sus expectativas de desarrollo personal, de inclusión en el mercado laboral y del acceso al posgrado. Los estudiantes creen que los psicólogos son importantes para la sociedad angoleña, marcada por una larga guerra civil, pues pueden contribuir a superar el sufrimiento emocional y la organización social en tiempos de paz.

Palabras clave: Juventud. Universitarios angoleños. Trayectoria. Licenciatura en Psicología.

\section{Introdução}

ste artigo apresenta a pesquisa realizada sobre a trajetória dos jovens angolanos oriundos das províncias e que migraram para Luanda, a capital do país, a - fim de realizarem o curso de Psicologia na Universidade Agostinho Neto (UAN). Para alcançarmos os objetivos do estudo, utilizamos duas estratégias metodológicas: a aplicação de 72 questionários entre os alunos dos primeiro e quarto anos do curso e, após a análise dos questionários, foram realizadas 10 entrevistas semiestruturadas, sendo 5 com os alunos ingressantes e $5 \mathrm{com}$ os formandos. Para resgatarmos a história da fundação do curso de Psicologia e 
conhecermos o seu projeto político-pedagógico, foi realizada uma entrevista com o coordenador do Curso de Psicologia da Faculdade de Letras e Ciências Sociais da UAN.

Inicialmente apresentamos um breve quadro do surgimento das universidades no contexto angolano e da situação do jovem em Angola. Em seguida, apresentamos as expectativas dos estudantes de Psicologia diante de sua formação e do futuro exercício profissional.

\section{Contexto angolano}

Em 1975, Angola, antiga colônia portuguesa, conquistou sua independência. O território angolano é atualmente dividido em 18 províncias e 173 administrações municipais. A capital do país é a cidade de Luanda, localizada na Província com o mesmo nome. Luanda é a província de Angola com maior densidade populacional, a mais escolarizada e industrializada, com elevado nível de crescimento econômico, que se deveu ao fato de praticamente não ter sofrido diretamente os efeitos da guerra civil.

De acordo com os dados divulgados pelo Instituto Nacional de Estatísticas (INE, 2012), a população angolana foi estimada em 18.576.568 de habitantes, dos quais 8.999.568 são homens e 9.577.494, mulheres. Desse universo, 46,6\% da população têm menos de 15 anos de idade e $68 \%$ da população total, menos de 35 anos. Quanto à expectativa de vida, a mesma fonte revela que, entre os homens, a média é de 46 anos, enquanto que para as mulheres é de 50 anos (Instituto Nacional de Estatísticas de Angola [INEA], 2012). Como se pode observar, Angola é um país de jovens.

A Constituição da República de Angola (Constituição de Angola, 2010) define o jovem como aquele que tenha entre 18 e 35 anos de idade. A maioridade legal é conferida a todos os que atingem 18 anos de idade. Nessa fase da vida, a pessoa recebe o estatuto de jovem e passa a pertencer à população ativa, com direitos e deveres de participar na vida política do país, ou seja, passa a exercer o direito e o dever de votar e o direito de se candidatar nas eleiçõos, e também o de trabalhar legalmente. Em um país de população jovem e com condições socioeconômicas fragilizadas, a escolarização em todos os níveis torna-se imperiosa, pois a educação é uma poderosa arma para a melhoria das condições de vida da população. Os desafios no campo educacional em Angola são imensos, pois muitos jovens precisam completar a escolarização fundamental e média, interrompida no período da guerra civil, para que possam continuar os seus estudos no nível universitário. 
$\mathrm{Na}$ história da universidade angolana, encontramos três marcos, como relata Mateus (2009): ainda no período colonial, houve a primeira tentativa de implantação, em 1789, do Curso Superior de Medicina, nomeado como "Aula de Medicina e Anatomia de Luanda", que, diante da falta de recursos humanos e materiais, e da ausência de demanda significativa de estudantes, foi logo extinto.

\begin{abstract}
A Aula de Medicina e Anatomia de Luanda funcionava com corpo docente constituído por um médico militar e um cirurgião, mas apenas formou um aluno, que já possuía estudos de farmacopeia feitos na Metrópole. O seu diretor - José Pinto de Azevedo - chegou a publicar um livro de medicina intitulado Ensaios sobre algumas enfermidades em Angola (Mateus, 2009, p. 27).
\end{abstract}

Dois séculos depois, o ensino superior em Angola voltou a ser implantado, na década de 1960, ainda na vigência do regime colonial. Mateus (2009) afirma que o ressurgimento da universidade em Angola se deu numa complicada conjuntura socioeconômica, marcada por pressões internas e externas. Internamente, a classe burguesa colonial desejava que seus filhos continuassem os estudos superiores sem que tivessem de abandonar a Colônia para estudar em Portugal. Por isso exigia insistentemente a criação de uma instituição apropriada para cumprir a tarefa de educação de seus filhos. Por outro lado, a eclosão e a evolução da luta armada de libertação nacional (realizada pelos três movimentos:
a) Frente Nacional de Libertação de Angola (FNLA);
b) Movimento Popular de Libertação de Angola (MPLA); e
c) a União Nacional para Independência Total de Angola - Unita)

Impunham medidas que pudessem não somente manter uma coesão nacional e assegurar o controle político-administrativo da Colônia como também contribuir para melhorar a situação nos domínios econômico, social e cultural, condição indispensável ao desenvolvimento interno, e para arrefecer os movimentos emancipatórios. No plano externo, Portugal era pressionado pelos organismos internacionais a melhorar as condições econômicas, sociais e educacionais das suas colônias na África. 
O terceiro marco no percurso histórico da universidade angolana foi a Proclamação da Independência do país, em 1975, quando o MPLA assumiu a condução do país com o propósito de combinar a construção nacional de Angola com a construção de uma sociedade socialista, de cunho marxista-leninista. A política educacional adotada seria subordinada aos princípios ideológicos do governo.

Paralelamente à Independência, eclodiu a guerra civil, que se prolongou até 2002, com algumas tréguas. Uma guerra, portanto, que durou 27 anos e que apresentou um saldo aproximado de 500 mil mortes e um fluxo migratório interno que atingiu mais de um milhão de habitantes, obrigados a deslocamentos constantes para se proteger dos combates. Evidentemente, as universidades sofreram um grande abalo durante esse período.

O MPLA, grupo que saiu vitorioso da guerra civil, assumiu o comando do país em 2002 e permanece no governo até os dias atuais. Na última década, percebese um grande esforço para a ampliação e a descentralização das instituições universitárias no país, uma vez que a concentração dos cursos universitários em Luanda, até aproximadamente 2005, dificultava o acesso de um contingente mais expressivo de jovens às universidades: devido aos custos, apenas um número restrito de pessoas conseguia deixar suas cidades de origem para dar prosseguimento aos seus estudos na capital de Angola.

O primeiro curso para a formação de psicólogos de Angola foi criado em 2003, na Universidade Agostinho Neto (UAN), e integrou a Faculdade de Letras e Ciências Sociais. O coordenador do curso, Prof. Carlinhos Zassara, informou que os cursos de Psicologia anteriores apenas formavam professores de Psicologia para lecionarem no ensino médio. Esses professores manifestaram interesse pela criação de um curso de Psicologia, e se organizaram para formular o projeto pedagógico.

O projeto inicial tinha como objetivo formar psicólogos para atuação nos campos da Psicologia Clínica, Psicologia Jurídica, Psicologia Escolar, Psicologia do Trabalho e Psicologia Social. O curso teria duração de cinco anos. O projeto foi aprovado, em 2003, pelo Conselho de Ministros e implantado no mesmo ano. Após o primeiro ano de funcionamento, o projeto inicial foi revisto, realizandose uma reforma do currículo e a redução da duração do curso de cinco para quatro anos, atendendo à orientação da Reitoria da UAN e do Ministério da Educação de Angola.

Para a formação das primeiras turmas, a UAN contou com a cooperação acadêmica entre Angola, Brasil e Congo. Atualmente, muitos graduados em Psicologia da UAN já concluíram também cursos de pós-graduação e se inseriram na Universidade como professores. 
A demanda pelo curso de Psicologia é significativa, e a UAN recebe entre 1.000 e 1.200 candidatos, que concorrem a aproximadamente cem vagas. Embora as instituiçôes universitárias tenham se expandido pelas províncias, a migração interna de estudantes ainda é grande, pois, muitas vezes, os jovens não encontram nas universidades de sua província o curso que desejam realizar.

As relações entre os jovens e a universidade em Angola têm interessado a vários pesquisadores angolanos, inseridos em diversas áreas do conhecimento, tais como: Pedagogia, Sociologia, Psicologia, Serviço Social, Filosofia, entre outras. No entanto, a pesquisa bibliográfica revelou que ainda são escassos os estudos sobre a juventude angolana, especialmente sobre a juventude universitária em Angola. Encontramos a tese de doutorado de Samba (2012), que trata dos significados do trabalho informal realizado por jovens migrantes em Luanda e exemplifica a tônica dos estudos encontrados que tratam do êxodo rural, do desemprego e do trabalho precário dos jovens em Angola.

A juventude angolana enfrenta muitos desafios. É vista de forma ambígua, ora ressalta-se o seu potencial de trabalho e de participação social e política na reconstrução da sociedade angolana, ora é vista com desconfiança e reduzida a um "problema social" a ser contido. A visão de que a juventude é uma etapa da vida de preparação para o futuro, muitas vezes, acaba por retirar do jovem a possibilidade de participar, de tomar decisóes no tempo presente. Ainda que o jovem seja visto como um sujeito de direitos, muitas vezes não é compreendido como sujeito político, capaz de exercício de cidadania e de expressar com sua própria voz suas demandas e decisões.

Nesse sentido, a discussão sobre os jovens estudantes angolanos encontra eco em Castro (2011), quando a autora aponta que muitas sociedades, em diversas épocas, consideravam "os jovens como aprendizes, como aqueles que não sabiam nem de si, nem do mundo e, como tal, deveriam se mostrar submissos às referências simbólicas das gerações anteriores" (p. 302).

Quando se fala em ser jovem, está-se a falar de um estilo de vida que vai além da definição da idade, mas que se associa à potencialidade de construção de uma sociedade melhor. Para Pais (2003), a definição da juventude em termos etários deve ser compreendida como um critério utilizado nos estudos demográficos e estatísticos, e na institucionalização das idades próprias para as etapas de escolarização ou para a responsabilização jurídica e social dos sujeitos, pois a idade por si só não define a juventude como uma categoria ou um estilo de vida.

Pais (2003) considera que é bastante comum não somente associar a juventude à faixa etária, mas também à "imaturidade psicológica". Tratar os jovens como "imaturos" e "irresponsáveis" significa excluí-los das decisões políticas, da participação social e comunitária. 
A pesquisa sobre a trajetória dos jovens universitários em Angola pautouse por considerá-los como sujeitos ativos e capazes de expressão e elaboração de suas próprias experiências. Buscou-se compreender que as experiências singulares dos jovens não estão apartadas das experiências coletivas vividas na sociedade angolana. Nesse sentido, é preciso criar espaços para que os jovens possam comunicar as suas experiências e criar formas inovadoras de participação social. Castro (2011) explica:

A comunicação com os jovens é necessária, porque consolida a esfera pública em regimes democráticos, para um processo global de aquisição de competências intelectuais, no qual emerge uma identidade descentralizada cognitiva e psicologicamente de uma sociedade ( $\mathrm{p}$. $315)$.

A construção do campo de pesquisa trouxe elementos importantes para a compreensão dos jovens universitários angolanos. Convidados a participar da pesquisa, a primeira reação foi de certo estranhamento diante da possibilidade de relatarem suas experiências e expectativas de futuro, bem como de manifestarem suas opiniōes, demandas e críticas ao contexto universitário. Vencida essa primeira impressão, as informações que os estudantes forneceram no preenchimento dos questionários e nas entrevistas realizadas foram fundamentais para desenhar o quadro de uma juventude plural e ativa.

\section{Os jovens estudantes de Psicologia: trajetórias e expectativas}

Para compreendermos a trajetória dos estudantes universitários angolanos que migraram das províncias para desenvolver seus estudos universitários em Luanda, buscamos o conceito de trajetória em Bourdieu (2010):

A vida é como um caminho, um percurso, uma estrada, com suas encruzilhadas (Hércules entre o vício e a virtude), ou como uma caminhada, isto é, um trajeto, uma corrida, um cursus, uma passagem, um percurso orientado, um deslocamento linear, unidirecional (a mobilidade), que comportam um começo (um início de vida), etapas, e um fim no sentido duplo, de termo e de objetivo (ele fará seu caminho, significa: ele terá sucesso, ele fará uma bela caminhada), um fim da história (p. 74).

Interessou-nos compreender o ponto de partida dos estudantes de Psicologia da Faculdade de Ciências Sociais da UAN, e o modo como traçaram suas metas 
e suas expectativas quanto ao final do curso, que se torna novo ponto de partida para a carreira profissional.

Foram utilizadas duas estratégias metodológicas: o questionário e a entrevista semiestruturada individual. A condição para a inclusão dos estudantes na pesquisa era a de serem oriundos de uma província do interior de Angola e terem migrado para Luanda para realizar o curso de Psicologia. Outro critério inicial era que os sujeitos tivessem idade entre 18 e 35 anos, faixa etária que define, segundo a Constituição angolana, a pessoa jovem. Este último critério sofreu uma pequena modificação, que permitiu a inclusão na fase de entrevista de um sujeito de 37 anos. A decisão foi tomada tendo em vista que o contexto da longa guerra civil acarretou múltiplas interrupções do processo de escolarização de vários cidadãos angolanos.

O contato com os estudantes foi intermediado pelo coordenador do curso, e todos foram informados dos objetivos da pesquisa e esclarecidos quanto ao caráter voluntário de sua participação. Além disso, foi também acordado que a identidade dos participantes seria preservada. Assim, são fictícios todos os nomes mencionados na dissertação (Chioia, 2012), nos artigos científicos e na apresentação do trabalho em congressos.

A pesquisa foi proposta aos alunos iniciantes do primeiro ano e aos formandos do quarto ano. Esse critério de escolha baseou-se na hipótese de que os alunos iniciantes estariam elaborando suas primeiras experiências universitárias no novo contexto, enquanto os formandos teriam elementos para avaliar a própria trajetória na universidade e projetar a sua carreira profissional.

A pesquisa foi iniciada com a aplicação de um questionário, organizado em dois blocos, aos alunos do primeiro e do quarto anos. O primeiro bloco continha questôes de identificação do aluno que se resumiam a: nome, idade, sexo, estado civil, nível acadêmico, província de origem, município, bairro, província de residência atual, município, bairro, faculdade, emprego, renda mensal e condição do aluno (bolsista ou não).

O segundo bloco foi organizado em nove perguntas abertas, das quais destacamos:

a) como o aluno tomou conhecimento da existência do Curso de Psicologia da Universidade Agostinho Neto;

b) quando o aluno decidiu estudar em Luanda e se buscou apoio;

c) se o aluno chegou à Universidade por meio de bolsa;

d) caso seja bolsista, qual é a instituição que o apoia; 
e) caso não tenha bolsa de estudos, quem assume as suas despesas;

f) se a Universidade responde às suas expectativas;

g) se, em sua opinião, a Universidade deveria ter um programa de apoio para os alunos provenientes de outras províncias;

h) se estaria disponível a continuar a participar da pesquisa nas etapas seguintes, a da entrevista individual e do grupo focal.

Os critérios para a inclusão dos estudantes na pesquisa não eram conhecidos a priori. Desse modo, foi necessária a aplicação do questionário a todos os alunos que se dispuseram a respondê-lo. As respostas foram analisadas, e foram encontrados 21 respondentes que atendiam aos critérios preestabelecidos. Sua faixa etária variava entre 22 e 37 anos. Dez eram do sexo masculino e 11 do sexo feminino, totalizando 21 alunos. A maioria era originária da Província de Uíge, com 8 alunos; vindos da Província de Malanje, 3 alunos; das Províncias do Huambo, Zaire, Kwanza-Norte vieram 2 alunos de cada uma; por último, das Províncias de Bengo, Cabinda, Cunene e Kwanza-Sul veio 1 aluno de cada uma delas.

Quando questionados a respeito de como tomaram conhecimento da existência do curso de Psicologia na UAN, a maioria (10 alunos) declarou que os professores do ensino médio os haviam informado do curso. Os amigos foram apontados como a segunda fonte de informação, e a mídia como a terceira.

Nas informações dadas pelos universitários, aparece um dado muito interessante, que se refere ao papel desempenhado pelos professores que atuam no ensino médio nas Províncias, não somente de passar aos alunos as informações sobre a existência dos cursos universitários em outras cidades do país, mas de incentivá-los a prosseguir seus estudos.

Para viabilizar a decisão do jovem de ir estudar em Luanda, o apoio dos pais e dos demais familiares foi fundamental para a maioria. No entanto aproximadamente um terço dos estudantes declarou que não recebeu apoio de ninguém. A maioria dos universitários representa os pais como fonte de segurança e apoio para a realização de seus anseios. Mesmo que os pais não estejam mais trabalhando, para muitos jovens, devem continuar a ajudar os filhos sempre que estes precisarem de alguma coisa, incluindo a formação.

Os 21 alunos prestaram o exame de seleção para a admissão na Universidade, mas nenhum deles tinha bolsa de estudos. As bolsas de estudo em Angola são de responsabilidade do Instituto Nacional de Bolsas de Estudos (INABE). Para que o aluno faça jus à bolsa, é preciso atender a critérios, tais como: 
a) frequentar o ensino superior em Angola;

b) viver em coabitação, independentemente da sua idade e da sua situação profissional;

c) que o rendimento mensal do agregado familiar seja inferior a quatro salários mínimos (aproximadamente 110 dólares);

d) residir na localidade onde se encontra o estabelecimento de ensino;

e) ter a idade-limite de 25 anos para a frequência a cursos de graduação e 35 anos para a frequência a cursos de pós-graduação;

f) ter notas superiores no histórico escolar do ensino médio (caso seja recém-chegado à Universidade); e

g) uma declaração com notas altas para os alunos do $2^{\circ}$ e $3^{\circ}$ anos da Universidade.

Sergio (2012) explica que muitos bolsistas do INABE, em várias províncias, passam meses sem receberem subsídio, e que os estudantes que não têm bolsa, para não abandonarem o curso universitário, fazem o comércio ambulante (zunga) após as aulas, para poderem pagar as suas contas.

Os alunos que participaram da pesquisa são migrantes, não puderam pleitear a bolsa de estudos, pois o plano de bolsas internas ainda tem limitações, já que não oferece ao aluno oportunidade de ir estudar em uma província distinta daquela na qual habita, onde esteja o curso do seu agrado.

Os respondentes declararam que suas despesas mensais para que possam se manter na Universidade são de 220 a 330 dólares. Para diminuir os custos, eles buscam moradias nos arredores de Luanda.

Em sua maioria, declararam que a Universidade tem respondido parcialmente às suas expectativas. Os que declararam que a Universidade não tem atendido às suas expectativas são, em sua maioria, do quarto ano. O ingresso na Universidade, no entendimento de alguns jovens, não objetiva somente a obtenção de diploma ou garantia do emprego qualificado, eles ressaltaram que a Universidade é também um espaço de convívio, sociabilidade e interaçôes afetivas entre os jovens.

Quando perguntados se desejavam que a Universidade tivesse um programa de apoio aos estudantes oriundos do interior do país, todos foram unânimes em afirmar que seria desejável que a Universidade desenvolvesse um projeto de apoio não somente financeiro, mas também psicossocial. 
Após a análise dos questionários, foram realizadas 10 entrevistas, 5 com homens e 5 com mulheres entre 37 e 22 anos, dos quais 8 eram solteiros, 1 estudante divorciado e 1 estudante casada. Cinco estavam iniciando o curso e 5 em fase de conclusão.

As entrevistas, sempre com o consentimento dos depoentes, foram gravadas. Após a transcrição, foram consideradas sob a perspectiva da análise qualitativa de conteúdo. De acordo com Franco (2008), o eixo central da análise de conteúdo é a mensagem verbal, gestual ou silenciosa transmitida pelo entrevistado, expressando significados e sentidos construídos que somente podem ser compreendidos no contexto sócio-histórico dos sujeitos. Sendo a entrevista uma interação social, ela própria é lócus de produção discursiva. No entanto, além do contexto sócio-histórico dos entrevistados, também se considera a qualidade da interação entre entrevistador e entrevistado como um elemento essencial na condução da análise do conteúdo das entrevistas.

Foram elaboradas, a priori, quatro categorias de análise, derivadas do problema de pesquisa, do questionário e do roteiro de entrevistas. Franco (2008) explica que "a categorização é uma operação de classificação de elementos constitutivos de um conjunto, por diferenciação seguida de um reagrupamento baseado em analogias, a partir de critérios definidos" (p. 59). As categorias que se destacaram foram:
a) motivos para estudar na Universidade em Luanda;
b) responsabilidade e mudança na Universidade;
c) tratamento recebido na Universidade;
d) Psicologia e
e) projetos profissionais.

A primeira categoria indica que o motivo principal apresentado pelos entrevistados para saírem de suas províncias em direção a Luanda foi o desejo de se tornarem psicólogos, formação não oferecida nas universidades locais. Ester, aluna do primeiro ano, nos diz: "Eu não queria fazer Psicologia no ramo da Educação". Como vimos, antes da criação do primeiro curso para a formação de psicólogos, havia cursos superiores de Psicologia, mas com o propósito de formar professores para o ensino médio. 
Elizabeth, que faz o último ano do curso de Psicologia do Trabalho, apresenta a mesma motivação: "Eu, desde sempre, quis fazer Psicologia Criminal; mas lá só tem Psicologia da Educação e não outro ramo, eu não queria e preferi vir aqui em Luanda fazer o curso que eu tanto quis".

Além dessas duas alunas, Zezinho segue a mesma linha de pensamento. Ele afirma que sonhava em ser atleta de futebol, mas as circunstâncias da vida não lhe deram oportunidade. Então ele diz: "Preferi fazer a Psicologia e, dentro da Psicologia, tem o ramo da Psicologia do Desporto, ou Psicologia Desportiva".

Isso indica que existe um desencontro entre a demanda dos jovens de se tornarem psicólogos e a oferta maciça pelo Estado angolano de cursos de Psicologia voltados para a área da Educação, ou seja, para a formação dos professores, em quase todas as províncias do país.

A responsabilidade e a mudança são uma moeda de duas faces e representam a segunda categoria. Só pode existir mudança quando o sujeito assume sua responsabilidade. Todo ser humano é responsável por seus atos; e quando toma para si mais outra tarefa, aumenta a responsabilidade que já carrega. Isso aparece mais claro para os jovens entrevistados. Ana, aluna do primeiro ano, conta: "Me sinto mais responsável, mais ocupada depois de estar na Universidade". Zezinho também afirma: "Há mais responsabilidade de minha parte, aquelas coisas que eu fazia nos tempos livres já não as faço, mas acho que aumentaram as minhas responsabilidades desde que estou na Faculdade".

Os universitários reconhecem a mudança em relação ao comportamento anterior, gerada pela responsabilidade em estudar na Universidade. Ester, aluna do $1^{\circ}$ ano, expressa: "Eu mudei muito na minha maneira de pensar e de encarar as coisas". Já Joãozinho, aluno do último ano, diz: "Eu mudei muito e tenho feito esforço para mudar mais; porque eu era muito impaciente com os outros e hoje ganhei $60 \%$ da paciência depois de estar no curso de Psicologia”. Quem também concorda com a mudança depois de estar no curso de Psicologia é Ludmila, aluna do último ano. Ela narra:

Eu noto mudança no meu comportamento e na forma de encarar as coisas; eu, antes, não entendia muito bem por que as pessoas eram muito diferentes umas das outras. Agora já entendo que cada um tem a sua personalidade e age de diferente forma.

\section{O mesmo ocorre com Augusto:}

Em mim próprio, há grande mudança, fico muito contente e satisfeito pela mudança em mim próprio; já não sou o Augusto de ontem, as pessoas que me rodeiam veem mudança em mim e eu próprio também noto isso. Sinto orgulho pela mudança que se operou em mim. 
A responsabilidade é associada pelos jovens à maturidade. É assim que Didi entende: "Estou a me considerar mais crescido, já estou a mudar nas atitudes; porque certas coisas que eu fazia no passado já não as faço mais”.

A entrada na universidade é considerada pelos estudantes como um elemento de mudança subjetiva. Por outro lado, a saída da casa dos pais e o afastamento dos demais membros da família tornam esses jovens responsáveis por administrar o seu cotidiano, o seu tempo, os recursos financeiros, o que também é considerado por eles como experiências que concorrem para o próprio amadurecimento.

A Psicologia como ciência que estuda o comportamento e os processos psicológicos do ser humano esteve presente na vida dos participantes, pois, antes de se tornarem estudantes de Psicologia e futuros psicólogos, eles tinham algumas representações sobre a ciência psicológica e o papel do psicólogo. $\mathrm{Na}$ entrevista, os jovens afirmam a importância de estudar Psicologia. Zezinho diz: "Sempre foi meu desejo estudar Psicologia". Já Rinói fala: "Escolhi a Psicologia por ser a ciência que estuda o homem". Elisabeth também vê na Psicologia a conquista do seu sonho: "Eu sempre quis fazer Psicologia para entender o meu comportamento e depois dos outros".

Os jovens têm a noção da importância da Psicologia numa sociedade como Angola. Joãozinho comenta: "A Psicologia é interessante na sociedade angolana, visto que o país ficou quase três décadas em guerra e, neste momento, está em paz, precisa de psicólogos para ajudar as pessoas a ter um comportamento digno". Augusto escolheu a Psicologia para aprender mais coisas e poder transmiti-las à sociedade angolana. No entender dele, a sociedade caminha para o mal: "É difícil acreditar nas coisas que as pessoas fazem, não tem explicação para a sociedade; principalmente os jovens e até mais velhos se comportam muito mal”.

A Psicologia pode ajudar as pessoas a ter um relacionamento saudável, no entendimento dos alunos. Formosa, aluna do último ano, fala: "Fiz uma escolha acertada, gostei muito e já sei como se deve relacionar com as outras pessoas". Didi, que exerce a profissão de fotógrafo e é aluno do primeiro ano, narra: "Eu trabalho com muitas pessoas e escolhi a Psicologia para me ensinar a ter um comportamento aceitável com os meus clientes".

Os universitários reconhecem a importância da Psicologia quando dizem que "a Psicologia estuda o comportamento do homem e está relacionada com a Medicina”. Para eles, uma sociedade sem psicólogos estará "desorientada”, e é por isso que a sociedade luandense deve formar psicólogos para ajudarem a resolver os problemas que as pessoas enfrentam. 
Quanto ao tratamento dispensado pela universidade aos alunos, os entrevistados entendem que a universidade não pode limitar-se à formação da geração jovem para o trabalho, mas também deve atender às necessidades pessoais e sociais desses jovens. Os dois grupos expressaram claramente essa ideia: "Nunca recebemos tratamento diferente; o tratamento que dão aos alunos daqui é o mesmo que dão a nós que viemos de outras províncias para vir estudar aqui”. A universidade deve conhecer as origens dos seus alunos para poder atendê-los. Ludmila fala: "A Faculdade não sabe que eu vim de Malanje". Mesma opinião de Elisabeth: "A Faculdade não sabe que eu vim de outra Província para estudar aqui". Ao afirmar que a universidade não conhece sua origem, Elisabeth está dizendo que a universidade não conhece as suas necessidades, os seus sentimentos por estar afastada de sua família, de seu grupo de amigos.

$\mathrm{O}$ ingresso de jovens na universidade enseja a convivência com outras pessoas antes desconhecidas e fortalece as amizades e o desenvolvimento da sociedade. $\mathrm{Na}$ entrevista com Augusto, está patente esse espírito quando diz: "Eu aqui não conhecia ninguém, mas hoje tenho colegas como amigos e colegas como irmãos". Joãozinho conta: "Eu tenho bom convívio com os colegas e professores".

A ação universitária não pode limitar o seu olhar à vertente de formação para o mercado de trabalho; ela pode desempenhar outras funções na formação dos jovens e abrir espaço de convivência entre eles, bem como os amparar na nova etapa da vida.

Quanto aos projetos profissionais, os entrevistados pretendem, após concluírem a graduação, continuar a formação nos níveis de mestrado e doutorado em Psicologia. É o que revela uma das entrevistadas: "Quando eu terminar a minha graduação, continuarei com os estudos para o mestrado e depois doutorado". Outro entrevistado diz: "Eu quero fazer o mestrado em Psicologia", e acrescenta: "Estou mesmo inclinado a estudar e depois penso em trabalhar".

Entre os planos de futuro estão aqueles relacionados à atividade profissional. Uns pensam em voltar à Província de origem para trabalhar, ajudar a família e a sociedade da sua cidade. É surpreendente notar que, entre a formação e o primeiro emprego, muitos jovens se dispóem a esperar o tempo que for necessário para obter um emprego na mesma área de formação. Didi fala: "Eu quero trabalhar no ramo de Psicologia". Já Ana afirma: "Eu gostaria de ser professora de Psicologia desta Faculdade”.

Nenhum entrevistado manifestou o desejo de deixar o curso de Psicologia. Outro aspecto interessante é que os estudantes de Psicologia compartilham a concepção de que o psicólogo tem um papel social na reconstrução de Angola. Eles entendem que a guerra civil deixou muitas marcas, muito sofrimento pessoal e coletivo, e que os psicólogos podem contribuir para a elaboração das vivências traumáticas pelas quais passou a sociedade angolana. 


\section{Considerações finais}

A categoria juventude é plural, diversa e, além disso, carrega potencialidades, ou seja, a juventude não pode ser tomada apenas como problema. A juventude está no tempo presente e não deve ser pensada somente na perspectiva do futuro. A população angolana é composta majoritariamente por jovens, e o Estado angolano deve efetivar políticas públicas que garantam os direitos sociais e civis da juventude, entre eles o direito à participação política, social e comunitária.

Desde o seu surgimento, a universidade em Angola passou por diversas metamorfoses; antes da Independência, era o lugar dos colonizadores e seus filhos; após a Independência, passou a servir aos interesses de toda a população angolana, ou seja, era um lugar de unificação do povo angolano; mas, lamentavelmente, a universidade não conseguiu expandir-se para todo o território, devido à guerra civil instalada no país após a proclamação da Independência nacional e que persistiu por 27 longos anos.

Os universitários que participaram desta pesquisa passaram por momentos de sofrimento ao longo das suas trajetórias, desde a infância, pois todos nasceram no período do conflito armado em Angola; suas vidas foram atravessadas pela insatisfação, pela falta de quase tudo de que as crianças necessitam. Alguns deles moraram com parentes, para poderem cursar o ensino primário, outros chegaram a viver nos internatos para poderem concluir o ensino médio. Outros ainda, em consequência do avanço da guerra civil, experimentaram longos períodos de interrupção no processo de escolarização.

A chegada a Luanda, motivada pelo ingresso no curso de Psicologia da UAN, foi difícil para eles, principalmente nos primeiros dias, por uma série de razões, entre elas por estarem habituados à vida nas pequenas cidades; estar em Luanda é quase estar em sofrimento. Precisaram se adaptar ao novo contexto, o que exigiu mudanças no estilo de vida, hábitos de moradia, alimentação, maneiras de vestir, comportamento político, preferências religiosas, práticas culturais e linguísticas, confrontar-se com conflitos urbanos e com o transtorno do transporte público, entre outros.

Em seus depoimentos, expressaram certa decepção quanto à acolhida na universidade, pois a forma como são recebidos não responde às suas expectativas. Criticaram a demora em obterem as declarações de que necessitam. Queixaramse de alguns professores não muito afetivos e até mesmo ríspidos. Esses jovens são, em sua maioria, de famílias pobres, arriscam-se a estudar em Luanda, onde enfrentam dificuldades de várias ordens, sem contar com apoio institucional. 
Embora atravessem dificuldades em Luanda, estudar na universidade é a grande realização dos seus sonhos, pois, na universidade, têm relaçôes boas com colegas e com alguns professores, tentam organizar as suas vidas para poderem concluir o curso e, futuramente, inserir-se no mercado de trabalho como psicólogos. Para outros, no entanto, não importa onde venham a trabalhar, ou se não exercerão a profissão de psicólogo, pois o necessário é ter o emprego que lhes permita ajudar suas famílias, ou seja, gerar renda como meio de sobrevivência autônoma. Alguns desejam voltar para a cidade de origem, outros querem permanecer em Luanda para dar continuidade aos estudos no nível da pós-graduação.

No momento de realização da pesquisa, o curso de Psicologia da UAN completou nove anos de existência. A Universidade reconhece que necessita aprimorar suas instalações, ampliar laboratórios, bibliotecas, salas de aula e cantinas. Além disso, dado o fluxo de estudantes originários do interior do país, considera necessária a implantação de serviço social, posto médico e um serviço de Psicologia para o atendimento psicossocial dos alunos. Espaços para atividades esportivas são também uma reivindicação dos alunos, pois entendem que a prática de esportes coletivos contribui para a convivência social entre eles.

Além das atividades de ensino, espera-se que as universidades angolanas invistam na extensão e na pesquisa, atividades universitárias fundamentais. A aproximação dos estudantes de Psicologia com as atividades extramuros, na forma da extensão e da pesquisa, poderá contribuir muito para que o curso de Psicologia possa formar psicólogos com competência e habilidade para compreender e intervir na realidade angolana, nas áreas da saúde, da educação, do trabalho, entre outras.

\section{Referências}

Bourdieu, P. (2010). Razôes práticas: sobre a teoria da ação. (Maria Corrêa, Trad.). Campinas: Papirus.

Castro, Lucia Rabello de. (2011). Os jovens podem falar?: sobre as possibilidades políticas de ser jovem hoje. In: D. Juarez, M. I. C. Moreira \& M. Stengel (Org.), Juventudes contemporâneas: um mosaico de possibilidades. Belo Horizonte: PUC Minas

Chioia, P. F. (2012). O jovem e a universidade em Angola: a trajetória dos jovens angolanos do interior do país no curso de Psicologia na Universidade Agostinho Neto. (Dissertação de Mestrado). Programa de Pós-graduação em Psicologia, 
PUC Minas, Belo Horizonte. Recuperado a partir de http://www.sistemas. pucminas.br/BDP/SilverStream/Pages/pg_ConsAreaConcentracaoDet02. html

Constituição de Angola. (2010). Diário da República, Angola, 5 fev. Recuperado a partir de http://www.tribunalconstitucional.ao/uploads/\%7B9555c6358d7c-4ea1-b7f9-0cd33d08ea40\%7D.pdf

Franco, M. L. P. B. (2008). Análise de conteúdo. Brasília: Liber Livro.

Instituto Nacional de Estatísticas de Angola. (2012). Recuperado a partir de http://www.ine.gov.ao/xportal/xmain?xpid=ine

Mateus, Pedro Antônio. (2009). A universidade em Angola: fatores que contribuiram para a criação do ensino superior em Angola. (Monografia de conclusão do curso). Universidade Agostinho Neto, Instituto Superior de Ciências da Educação, Luanda.

Pais, José Machado. (2003). Culturas juvenis. Lisboa: INCM.

Samba, Simão João. (2012). Significados do trabalho informal em Luanda: luta, coragem e persistência nas vozes dos jovens migrantes. (Tese de Doutorado). Pontifícia Universidade Católica de São Paulo, São Paulo. Recuperado a partir de http://www.sapientia.pucsp.br//tde_busca/arquivo.php?codArquivo=13882

Sergio, Paulo. (2012, 29 de agosto). Falta de subsídio leva bolseiro do Inabe a zunga. $O$ pais, Luanda. Disponível em: http://www.opais.net/pt/ opais?id=1657det $=28537$ 